\title{
Approaches for Departments, Schools, and Health Systems to Better Implement Technologies Used for Clinical Care and Education
}

\author{
Donald M. Hilty ${ }^{1}$ (I) · Jürgen Unützer ${ }^{2} \cdot$ Dong-Gil Ko $^{3} \cdot$ John Luo $^{4} \cdot$ Linda L. M. Worley $^{5} \cdot$ Joel Yager $^{6}$
}

Received: 6 September 2018 / Revised: 17 May 2019 / Accepted: 27 May 2019 / Published online: 6 June 2019

(C) Academic Psychiatry 2019

Rapidly shifting how health care and business are managed, technology can enormously impact the quality of service care delivery, education/training, faculty development, and administration in academic health centers [1,2]. While the shift to include technology is consistent with the Institute of Medicine's health professional education movement, the question is how to efficiently do that in a metric-, data-, and reimbursement-driven care era [3-5]. Leaders of departments, schools, and health systems are obliged to understand the external forces at play related to health care, which push for "faster, cheaper, better" services [6,7]. Technology creates challenges to overcome such as clinical competence, as well as uncertain cost and operational requirements [4].

To date, the most widely researched and implemented technology in psychiatric settings has been telepsychiatry (TP; video) or telebehavioral health (TBH). Randomized controlled trials show that TBH is effective and comparable to in-person care via a variety of models [8-11]. Guidelines by the American Telemedicine Association in 2013 and 2017 $[12,13]$ provide clinical, administrative, and technical contexts. Psychiatric leaders must now also consider social media, mobile health, apps, and other technologies — each associated with assorted benefits, risks, and costs.

Donald M. Hilty

donh032612@gmail.com

1 University of California Davis School of Medicine, Sacramento, CA, USA

2 University of Washington School of Medicine, Seattle, WA, USA

3 University of Cincinnati, Carl H. Lindner College of Business, Cincinnati, OH, USA

4 University of California, Riverside Health, Riverside, CA, USA

5 University of Arkansas for Medical Sciences, Little Rock, AR, USA

6 University of Colorado at Denver School of Medicine, Denver, CO, USA
This paper is designed to help leaders "step back" and broadly envision how academia and technology may reasonably interface. If psychiatric faculty and administrators fail to technologically progress, young professionals may opt toward other technology-hip areas of medicine, and clinical boundary and privacy violations may become more common. This paper complements the curricular and competency papers [14-18], which provide more operational, concrete examples for faculty, residents, and administrators. This paper aims to help readers in three ways:

1) To understand the technology-related skills, attitudes, and knowledge for clinicians and trainees to ensure the quality of care

2) To provide an approach to make change with technology: (1) assess readiness; (2) create/hardwire the culture; (3) write policies and procedures; (4) establish the curriculum and competencies; (5) train learners and faculty; and (6) evaluate/manage change

3) To provide principles of an approach in the form of institutional competencies to help integrate technology into core academic missions

\section{Technology-Related Skills, Attitudes, and Knowledge for Clinicians to Ensure Quality of Care}

\section{Technology and Clinical Care}

Technology may impact the therapeutic frame, trust/safety, and expectations [19, 20]. Clinicians can explore patients' requests, needs, and preferences about technology through the consent process, though some patients use technology spontaneously after the fact $[16,20]$. Regardless of the technologies used, the therapeutic frame must adhere to clinical, legal, and ethical mandates (e.g., planning for emergencies at a 
distance, privacy). Clinical care systems must specify how technology is used in personal versus professional relationships (e.g., text messages during business or after hours; not using personal cell phone for care). It is also important to clarify in which circumstances specific technologies should (or should not) be used (e.g., a telephone call instead of posting suicidal thoughts on social media). New options like "emoticons" or emojis are increasingly popular and contribute to social communication, but they have drawbacks, too. They may not adequately capture the nuances of feelings expressed in-person or by written words, and they may be confusing at times [18, 21, 22].

Technology-associated change impacts many areas of clinical care, training, and faculty development $[14,23]$. Areas being explored include the computer-based patient record or electronic health record (EHR) (e.g., workflow time and burnout) [24], adjustments of educational Milestones [25], technology-assisted clinical handoffs [13], social media use [16], electronic health portals [26], artificial intelligence for diagnosis [27], registries for clinical care and research [20], ediaries for longitudinal collection of patient symptoms [28], and use of email, apps, and games [20, 29, 30].

\section{Fundamental Steps for Departments and Systems to Implement and Evaluate Technology}

An approach to technology across clinical, academic, and administrative missions is suggested, since telepsychiatric services, social media, and other technologies are evolving quickly [14, 31-33]. The assessment of readiness for change is one of the several suggested institutional competencies [14]. Specific areas to evaluate are as follows: patient-centered care; evaluation and outcomes; roles/needs of participants (e.g., trainees, faculty, teams, professions); teams, professions, and systems within institutions; and the academic health center institutional structure, process, and administration.

To guide the process of implementing new technologies, a suggested approach is outlined: (1) assess readiness; (2) create/hardwire the culture; (3) write policies and procedures; (4) establish the curriculum and competencies; (5) train learners and faculty; and (6) evaluate/manage change.

\section{Assessing Readiness for Change}

Institutions have to assess readiness to change at the participant, program, and organizational levels (Tables 1 and 2). Individual participants (i.e., faculty, clinician, staff, and trainee) need to understand expectations (e.g., skills they will be expected to master), the degree of anticipated change, and the impact of change on day-to-day work; these matters affect morale and workplace climate. Programs need good communication,
Table 1 Checklist of factors to help organizations measure readiness and implement change with technology

Participant level: faculty, clinicians, staff, and trainee

1. Outline of skills, competencies, and best practices for change

2. Level of innovation required (i.e., incremental, radical, transformative)

3. Linkage of technology with health care outcomes and/or deliverables to end-user(s) (i.e., patient, staff, clinicians; trainees, faculty; interdisciplinary teams)

4. Rewards/incentives at all levels (what managers and employees get for changing)

5. Morale (spirit and trust in the workforce)

Program and system evaluation levels

6. Measurements (ways of determining achievement of change)

7. Organizational climate (context and events pertaining to the change)

8. Organizational structure (flexibility and stability)

9. Culture of quality improvement and prior experience with change (degree of success)

10. Ownership of all participants and responsive decision-making by leaders

Organization level

11. Sponsorship (endorsement of change from the top) and leadership (day-to-day support for change)

12. Motivation from top management to implement change and willingness of participants

13. Direction (clear vision of what should result from change)

14. Competitor benchmarking (how other competitors are doing with similar changes)

15. Communication (open, two-way) about the change involving technology

collaboration, and teamwork. Organizational-level sponsors must outline the motivations for change, communicate change plans, and provide context for necessity (e.g., comparing to competitors' initiatives) [34]. External consultants may help evaluate the organizational climate and the degree of participant flexibility.

Experience in both business and health care sectors suggests a cautious approach to change implementation $[35,36]$. Technology-associated innovation might be incremental, with minor changes to current services/products (e.g., add processes) or radical, via a major breakthrough or discovery. Transformative change may be simple and/or complex, but generates significant value. In the short term, disruptive innovation occurs if the focus is too big, only a minority of people is helped, a paradigm shift for many is needed, and other business practices are contradicted. In the long term, with patience and time, participants may feel empowered and see value in improved customer/patient service and efficiency.

Suggested strategies and steps are outlined in two tiers to provide options for departments and institutions. At a minimum, it is suggested to (1) assess clinical service technology platforms for video, e-mail, and other common technologies; and (2) assess structure/function of social groups of a 
Table 2 Competencies for institutions/academic health centers for telebehavioral health and e-competencies

\begin{tabular}{|c|c|c|c|}
\hline Competency focus & Foci & Evaluation & Tips related to technology \\
\hline Patient-centered care & $\begin{array}{l}\text { Input on care models and treatment } \\
\text { options } \\
\text { Offer multiple points-of-entry } \\
\text { Screen for technology use }\end{array}$ & $\begin{array}{l}\text { Assess the "whole-person," } \\
\text { customer service } \\
\text { (e.g., care coordination } \\
\text { and communication) }\end{array}$ & $\begin{array}{l}\text { Offer range of technology options } \\
\text { Import social science, health behavior, } \\
\text { and business ideas }\end{array}$ \\
\hline Evaluation and outcomes & $\begin{array}{l}\text { Link behavior to outcomes for a } \\
\text { patient or program } \\
\text { Use evidence-based measures }\end{array}$ & $\begin{array}{l}\text { Use a technology platform } \\
\text { Use technology-specific measures }\end{array}$ & $\begin{array}{l}\text { Use benchmark plan for clinical } \\
\text { accreditation: goal, measure, } \\
\text { benchmark, } \\
\text { target, and data }\end{array}$ \\
\hline Trainee/student needs/roles & $\begin{array}{l}\text { Patient- and learner-centered outcomes } \\
\text { Prepare as resource manager } \\
\text { Clarify personal versus professional } \\
\text { technology use }\end{array}$ & $\begin{array}{l}\text { Link supervision to care } \\
\text { and learner skills } \\
\text { Use } 360 \text { evaluation } \\
\text { Monitor wellness and } \\
\text { professionalism }\end{array}$ & $\begin{array}{l}\text { Use quantitative and qualitative } \\
\text { approaches } \\
\text { Use observation, video, and simulation } \\
\text { Role model healthy behaviors }\end{array}$ \\
\hline $\begin{array}{l}\text { Faculty clinical, teaching, } \\
\text { and leadership roles }\end{array}$ & $\begin{array}{l}\text { Emphasize communication, } \\
\text { wellness, and professionalism } \\
\text { Use technology as a lifelong } \\
\text { learner/teacher } \\
\text { Emphasize resource manager } \\
\text { technology leadership role }\end{array}$ & $\begin{array}{l}\text { Monitor wellness and } \\
\text { professionalism } \\
\text { Define success based on teams, } \\
\text { systems, and populations }\end{array}$ & $\begin{array}{l}\text { Use social science, health service, and } \\
\text { business constructs } \\
\text { Use longitudinal approaches } \\
\text { Use technology for portfolio, curricula, } \\
\text { dissemination, networking, and other } \\
\text { purposes }\end{array}$ \\
\hline $\begin{array}{l}\text { Teams, professions, and } \\
\text { systems within } \\
\text { institutions }\end{array}$ & $\begin{array}{l}\text { Assess structure/function of social groups } \\
\text { that govern behavior of a community } \\
\text { Use faculty development with teams, } \\
\text { projects, and professions to build skills }\end{array}$ & $\begin{array}{l}\text { Foster alignment across systems } \\
\text { Organize goals and outcomes for } \\
\text { success based on teams, systems, } \\
\text { and professions }\end{array}$ & $\begin{array}{l}\text { Align shared outcomes: } \\
\text { Patient/clinician outcomes } \\
\text { Learner/teacher } \\
\text { Clinic/system } \\
\text { Institution/community }\end{array}$ \\
\hline $\begin{array}{l}\text { AHC organizational } \\
\text { structure, process, } \\
\text { and finance }\end{array}$ & $\begin{array}{l}\text { Use technology platform } \\
\text { Weigh human resources, technology, } \\
\text { and cost issues } \\
\text { Build AHC-community partnerships } \\
\text { to share resources and integrate care } \\
\text { Align missions and values } \\
\text { Use faculty development projects } \\
\text { to shift culture }\end{array}$ & $\begin{array}{l}\text { Provide easy access } \\
\text { Assess context, pace, scope, } \\
\text { and drive of/for change } \\
\text { Be proactive not reactive } \\
\text { Strive for incremental, sustainable } \\
\text { solutions } \\
\text { Measure technology in performance } \\
\text { evaluations and provide feedback }\end{array}$ & $\begin{array}{l}\text { Monitor private, federal, state, } \\
\text { and other sectors } \\
\text { Seek technology grant funding } \\
\text { (e.g., Office for Advancement of } \\
\text { Technology) and partner with agencies } \\
\text { (e.g., Federal Communications } \\
\text { Commission) } \\
\text { Use/adapt others' evidence-based } \\
\text { system approaches }\end{array}$ \\
\hline
\end{tabular}

community to focus workflow changes and training. If resources are available, additional suggestions are to (1) assess need and capacity for advanced technologies (e.g., mobile health wearables, devices); and (2) assess the need for system-wide training and other interventions to move from current to target architectures.

\section{Create/Hardwire the Culture}

Since technology is a tangible part of health care and academic missions, adapting ideas from it use in business may be helpful. Fundamentally, progressive business practice has shifted information technology (IT) from an appendage to a core, integrated component. IT is now interlaced with research and development, marketing, production, and financing functions - as an organizing framework - and this is referred to as a shared IT-business understanding [37]. For health care, technology use requires clinical skills, technical support, and team workflow adjustment — so planning and evaluation must cover these landscapes.
As for strategies and steps, at a minimum, it is suggested to (1) prioritize telephone, e-mail, and video implementation before mobile health options due to ease, cost, and other factors; adjust the physical plant (i.e., lighting) and technology, if needed; and (2) select technology infrastructure platforms (e.g., the EHR) so in-person and TBH cares are integrated, support e-information flow, and assist health professionals' decision-making. If resources are available, additional suggestions are to (1) delegate a clinician champion and a teaching faculty to learn and implement clinical competencies to steer training and faculty development; and (2) design clinical technology workflows (e.g., a virtual waiting room), adjust policies and procedures, and assess if mobile health and social media platforms are needed.

\section{Write Policies and Procedures}

The overall administrative approach should attend to process, procedures, policy, and evaluation in order to plan, implement, and manage a program. Input from all levels of the 
organization - including clinician, manager, and technology stakeholders - should help ensure fidelity to the plan, reduce uncertainty, and improve effectiveness.

As for strategies and steps, at a minimum, it is suggested to (1) use/build templates for consent, intake, and ongoing care processes; and (2) amend and/or add departmental and system policies and procedures (e.g., policy on use of social media); evaluate if patients and clinicians are informed and adhere to these. If resources are available, additional suggestions are to (1) collaborate with school, health system, and community partners to support video use in clinical, educational, and research missions; and (2) build in a quality measure that can be used for in-person and TBH cares (e.g., Telemedicine Satisfaction Survey) from a lexicon of options [38, 39].

\section{Establish the Curriculum and Competencies}

Telepsychiatric $(2015,2018)$, broader TBH (2017), social media (2018), and mobile health (2019) competencies were designed to support clinical care, training, faculty development, and administrative missions [14-18]. Most frameworks use the Accreditation Council of Graduate Medical Education domains [25]. The original TP competencies were subdivided according to the Dreyfus model for learners into novice/ advanced beginner, competent/proficient, and expert levels $[14,18,40]$. Clinical and administrative-based issues related to care include documentation, EHR, medico-legal, billing, cultural, confidentiality, and privacy (e.g., Health Insurance Portability and Accountability Act; HIPAA) [14-18, 41].

Implementing an e-culture and teaching associated competencies successfully will likely require a mixture of methods to increase learners' skill level over time. The mixture may include clinical rotations, seminar, supervision, research/quality improvement projects, and case-based learning [14-18]. A framework for program evaluation [42] and Kern's six-step approach to curricular development are suggested: (1) problem identification, (2) needs assessment, (3) goals and objectives, (4) identifying educational strategies, (5) implementation, and (6) curriculum/ program evaluation and feedback [43]. Clinical informatics ideas are also available to help directors of training programs implement curricula and rotations with supervision [44].

As for strategies and steps, at a minimum, it is suggested to (1) embody technologies in the residency seminar(s) and offer TP clinical rotations, focusing on one competency each for telephone, e-mail, and video; and (2) encourage program and clerkship directors to select, develop, and adapt regular milestones to include technologically based competencies. If resources are available, additional suggestions are to (1) employ a multi-year residency curriculum including informatics, adjust core rotations, and add a required advanced-year clinical rotation in TP; this could include three competencies for video and one for mobile health and social media; and (2) identify a vice-chair of education (or clinical services) or other advanced career faculty members to promote technology and liaison with salient national psychiatric organizations.

\section{Train Learners and Faculty}

Faculty may be variably interested in TP/TBH practice, so all programs will best serve their trainees' professional development needs by identifying faculty thought leaders or champions of these increasingly important modalities. They can link to others through national educational organizations such as the American Association of Directors in Psychiatry Resident Training, Association For Academic Psychiatry, American Association of Technology in Psychiatry, and the American Directors of Medical Student Education in Psychiatry.

For technologies involving social media, the challenges are greater. Fortunately, some faculty already use social media for career development, professional advancement, and clinical and teaching purposes. Platforms such as Twitter $^{\circledR}$ and LinkedII ${ }^{\circledR}$ are extensively used internationally and provide a range of benefits for networking and promoting scholarshipnew, fast ways to disseminate innovations (e.g., electronic prepublishing of articles, blogs) [45, 46]. For social media, thought leaders and champions for education and implementation might well come from trainees as easily as from faculty, essentially instituting what the anthropologist Margaret Mead called a "prefigurative" learning culture, in which the young teach the old [47].

As for strategies and steps, at a minimum, it is suggested to (1) provide didactics (e.g., bedside, seminar, grand rounds) upon research, trends, and relevance of TP and to correct misconceptions; this may engage/interest learners in educational opportunities and provide content knowledge more than to develop attitudes and skills; and (2) use case-based learning to deepen content knowledge, to begin to apply and generalize knowledge to real-life examples, and to practice developing treatment/ management plans. If resources are available, additional suggestions are to (1) provide clinical rotations to practice skills related to patient care, gain exposure to various populations, observe role models, and obtain feedback from supervisors; and (2) use group observed, co-interviewing, and/or simulation to focus on engagement, interpersonal, and communication skills, and to build consensus on pros and cons of TP.

\section{Evaluate/Manage Change}

Change requires leadership and management approaches for technology across multiple clinical, academic, and administrative missions [14]. Change may be facilitated by use of opinion-leader visits and discussions, survey instruments, focus groups, site visits, in-person and on-line courses, and external consultants [48]. Inevitable, foreseen, and unforeseen negative consequences of such disruptions require skillful management $[34,35,49,50]$. 
As for strategies and steps, at a minimum, it is suggested to (1) evaluate both in-person and TBH cares with standard (i.e., Joint Commission) and supplemental (e.g., Telemedicine Satisfaction Survey) measures [37, 38]; and (2) provide funding infrastructure (e.g., pilot projects) to support technology-based evaluation and health services-based quality improvement projects. If resources are available, additional suggestions are to (1) add research and funding infrastructure for technology-based pilot and full-scale projects, focusing on those that impact health service delivery across training programs and services; and (2) advance academic and community missions via partnerships for video and other technology applications to clinical, educational, and research missions.

\section{Conclusions}

New technologies create opportunities and challenges that significantly impact education, health care, and business. Leaders in academic health centers and departments of psychiatry already exploring TP or TBH must also consider integrating social media, mobile health, apps, and other emerging technologies related to clinical care, training, faculty development, and administrative missions. Successful implementation of technology requires hands-on leadership, needs assessments, participation by all levels of the organization, and continuous quality/performance improvement to support a positive e-culture. Additional research is needed to develop consensus regarding priorities, prototypes, standardization, and best implementation strategies.

Acknowledgments The authors acknowledge the following: American Telemedicine Association, Telemental Health Interest Group; American Psychiatric Association, Telepsychiatry Committee; University of Arkansas of Medical Sciences; University of Cincinnati Lindner College of Business; Departments of Psychiatry and Behavioral Sciences: University of California, Davis; University of California, Riverside; University of Colorado at Denver; and University of Washington; Veterans Affairs Northern California Health Care System

\section{Compliance with Ethical Standards}

Disclosures On behalf of all authors, the corresponding author states that there is no conflict of interest.

\section{References}

1. Garber AM. Evidence-based guidelines as a foundation for performance incentives. Health Aff. 2005;24(1):174-9.

2. Hilty DM, Hwang T, Turvey C. Staying abreast of information in the information age: digital continuing education and levering technology to stay current for clinical psychiatric practice. Curr Psychiat Rep. 2018;12;20(3):15. https://doi.org/10.1007/s11920-018-0878-y.

3. Institute of Medicine. The core competencies needed for healthcare professionals. Health Professions Education: A Bridge to Quality.
Washington, DC: The National Academies Press; 2003. https://doi. org/10.17226/10681.

4. Centers for Medicare \& Medicaid Services, 2013. Coverage of direct service workforce continuing education and training within Medicaid policy and rate setting: a toolkit for state Medicaid agencies. https://www.medicaid.gov/medicaid/ltss/downloads/ workforce/dsw-training-rates-toolkit.pdf, p. 12.

5. Joint Commission. Measurement-based care in behavioral health, 2017. https://www.jointcommission.org/assets/1/6/bhc_Joint Commission_measures_webinar_041117.pdf

6. Danzon PM, Pauly MV. Insurance and new technology: from hospital to drugstore. Health Aff. 2001;20(5):86-100.

7. Akenroye TO. Factors influencing innovation in healthcare: a conceptual synthesis. The Innovat J. 2012;17(2):1-21.

8. Hubley S, Lynch SB, Schneck C, Thomas M, Shore J. Review of key telepsychiatry outcomes. World J Psychiat. 2016;6(2):269-82.

9. Hilty DM, Rabinowitz TR, McCarron RM, et al. An update on telepsychiatry and how it can leverage collaborative, stepped, and integrated services to primary care. Psychosomatics. $2018 \mathrm{http}: / /$ www.psychosomaticsjournal.com/article/S0033-3182(17)30267-0/ abstract;59:227-50.

10. Hilty DM, Ferrer D, Callahan EJ. The effectiveness of telemental health: a 2013 review. Tel J E-Health. 2013;19:444-54.

11. Fortney J, Pyne JT, Turner E, et al. Telemedicine integration of mental health into rural primary care settings. Int Rev Psychiat. 2015;27(6):525-39.

12. American Telemedicine Association, 2013. Practice guidelines for video-based online mental health services. http://www. americantelemed.org/docs/default-source/standards/practiceguidelines-for-video-based-online-mental-health-services.pdf? sfvrsn=6.

13. American Telemedicine Association, 2017. Practice guidelines for telemental health with children and adolescents. https:// higherlogicdown 1 oad.s 3 . a mazonaw s.com/ AMERICANTELEMED/618da447-dee1-4ee1-b941c5bf3db5669a/UploadedImages/Practice\%20Guideline $\%$ 20Covers/NEW ATA\%20Children\%20\&\%20Adolescents\% 20Guidelines.pdf

14. Hilty DM, Crawford A, Teshima J, Chan S, Sunderji N, Yellowlees PM, et al. A framework for telepsychiatric training and e-health: competency-based education, evaluation and implications. Int Rev Psychiat. 2015;27(6):569-92.

15. Maheu M, Drude K, Hertlein K, et al. An interdisciplinary framework for telebehavioral health competencies. J Tech Behav Sci. 2018;2:190-210. https://doi.org/10.1007/s41347-017-0038-y.

16. Zalpuri I, Liu H, Stubbe D, et al. A competency-based framework for social media for trainees, faculty and others. Acad Psychiatry. 2018;42(6):808-17.

17. Hilty DM, Chan S, Torous J, Luo J, Boland RJ. A telehealth framework for mobile health, smartphones and apps: competencies, training and faculty development. J Tech Behav Sci. 2018. https://doi. org/10.1007/s41347-019-00091-0.

18. Hilty DM, Maheu M, Drude K, et al. The need to implement and evaluate telehealth competency frameworks to ensure quality care across behavioral health professions. Acad Psychiatry. 2018;42(6): 818-24.

19. Hilty DM, Nesbitt TS, Marks SL, et al. How telepsychiatry affects the doctor-patient relationship: communication, satisfaction, and additional clinically relevant issues. Prim Psychiat. 2002;9(9):29 34.

20. Hilty DM, Chan S, Torous J, et al. New frontiers in healthcare and technology: Internet- and web-based mental options emerge to complement in-person and telepsychiatric care options. J Health Med Informat. 2015;6(4):1-14. 
21. Aldunate N, González-Ibáñez R. An integrated review of emoticons in computer-mediated communication. Front Psychol. 2017;6(7): 2061. https://doi.org/10.3389/fpsyg.2016.02061.eCollection 2016.

22. Walther J, D'Addario K. The impacts of emoticons on message interpretation in computer-mediated communication. Soc Sci Comput Rev. 2001;19(3):324-47.

23. Luo JL, Hilty DM, Worley LLM, et al. Considerations in change management related to technology. Acad Psychiatry. 2006;30(6): 465-9.

24. Shanafelt TD, Dyrbye LN, Sinsky C, Hasan O, Satele D, Sloan J, et al. Relationship between clerical burden and characteristics of the electronic environment with physician burnout and professional satisfaction. Mayo Clin Proc. 2016;91(7):836-48.

25. Accreditation Council on Graduate Medical Education, 2013. Common program requirements https:/www.acgme.org/ acgmeweb/Portals/0/PFAssets/ProgramRequirements/CPRs2013. pdf.

26. Strudwick G, Kuziemsky C, Booth RG, Collins S, Chyjek A, Sakal $\mathrm{M}$, et al. Engaging patients and family members in the evaluation of a mental health patient portal: protocol for a mixed-methods study. BMJ Open. 2018;8(8):e025508. https://doi.org/10.1136/bmjopen2018-025508.

27. Rush AJ, Ibrahim HM. Speculations on the future of psychiatric diagnosis. J Nerv Ment Dis. 2018;206(6):481-7.

28. Moskowitz DS, Young SN. Ecological momentary assessment: what it is and why it is a method of the future in clinical psychopharmacology. J Psychiat Neurosci JPN. 2006;31:13-20.

29. Ye J, Rust G, Fry-Johnson Y, Strothers H. E-mail in patientprovider communication: a systematic review. Patient Educ Couns. 2010;80(2):266-73.

30. Hilty DM, Chan S, Hwang T, Wong A, Bauer AM. Advances in mobile mental health: opportunities and implications for spectrum of e-mental health services. mHealth. 2017;21(3):34. https://doi. org/10.21037/mhealth.2017.06.02.

31. Kotter JP. Leading change. Why transformation efforts fail. Harv Bus Rev. 1995:59-67.

32. Rogers EM. Diffusion of innovations. fourth ed. New York: Free Press; 1995

33. Carr DK, Hard KJ, Trahant WJ. Managing the change process: a field book for change agents, consultants, team leaders, and reengineering managers. New York, NY: McGraw Hill; 1996. p. 115-40.

34. Steward TA. Rate your readiness to change. Fortune 1994; Feb 7: 106-107, 110.

35. Bower JL, Christensen CM. Disruptive technologies: catching the wave. Harv Bus Rev. 1995;73(1):43-53.

36. Christensen CM, Grossman JH, Hwang J. The innovators prescription - a disruptive solution for health care. New York NY: McGraw Hill; 2009.
37. Ray G, Muhanna WA, Barney JB. Competing with IT: the role of shared IT-business understanding. Asso Comput Machinery Commun ACM. 2007;50(12):87-91.

38. Agency for Healthcare Research and Quality (AHRQ). Telemedicine Satisfaction Survey), 2018. https://healthit.ahrq.gov/sites/default/ files/docs/survey/telehealthsatisfactionquestionnaire_comp.pdf

39. American Telemedicine Association, 2013. A lexicon of assessment and outcome measures for telemental health. Retrieved from https://www.providerexpress.com/content/dam/ope-provexpr/us/ $\mathrm{pdfs} / \mathrm{clinResourcesMain/tmh/ataLexicon.pdf}$

40. Dreyfus SE, Dreyfus HL. A five-stage model of the mental activities involved in directed skill acquisition. Berkeley, CA: University of California, Operations Research Center, 1980. https//:www.dtic. mil/cgi-bin/ GetTRDoc?AD=ADA084551.

41. Hilty DM. Advancing science, clinical care and education: shall we update Engel's biopsychosocial model to a bio-psycho-sociocultural model? Psychol Cogn Sci. 2016;1(1):e1-5. https://doi. org/10.17140/PCSOJ-1-e001.

42. Kirkpatrick J, Kirkpatrick W. The Kirkpatrick four levels: a fresh look after 50 years, 1959-2009. http://www.managesmarter.com/ managesmarter/images/pdfs/trg_20090417_kirkpatrickw hitepaper.pdf

43. Kern DE, Thomas PA, Hughes MT. Curriculum development in medical education: a six-step approach. Baltimore, MD: Johns Hopkins University Press; 2009.

44. Torous J, Chan S, Boland R, et al. Clinical informatics in psychiatric training. Acad Psychiatry. 2018;42(5):694-7.

45. Markham JM, Gentile D, Graham DL. Social media for networking, professional development, and patient engagement. Am Soc Clin Oncol Educ. 2017;(37):782-7.

46. Bernhardt JM, Alber J, Gold RS. A social media primer for professionals: digital do's and don'ts. Health Promot Pract. 2014;15(2): 168-72.

47. Flaherty RP. Margaret Mead, Prefigurative culture, and the digital generation, 2016. https://www.linkedin.com/pulse/margaret-meadprefigurative-culture-digital-robert-flaherty/.

48. Armenakis AA, Harris SG, Mossholder KW. Creating readiness for organizational change. Hum Relat. 1993;46:681-703.

49. Dye CF. Leadership in healthcare: essential values and skills, second edition. Chicago, IL: Health Administration Press; 2010.

50. Shi L, Singh DA. Delivering health care in America: a systems approach. sixth ed. Burlington, MA: Jones and Bartlett Learning; 2015. p. 1-21.

Publisher's Note Springer Nature remains neutral with regard to jurisdictional claims in published maps and institutional affiliations. 